\title{
Effect of Operating Temperature on CI Engine Performance Parameters with Diesel \& Jatropha Bio-diesel
}

\author{
[Karsoliya R.P., Mandloi R.K.]
}

\begin{abstract}
India is among those tropical countries where atmospheric temperature is having very vast range i.e. from $0^{\circ} \mathrm{C}$ to $48^{\circ} \mathrm{C}$ in various regions of the country. This vast varying temperature range may not allow the engine to perform uniformly, therefore, which temperature is most suited for operating parameters of engines and will give the best performance levels. The aim of this study is to analyze the performance of a compression ignition (CI) engine using Jatropha biodiesel and its blends with diesel as fuel on changing engine temperature to obtain best performance levels. It has been tried to investigate the optimum operating temperature of engine that will deliver the best performance level. The blends of Jatropha with diesel in varying proportions (B10, B20 and B40) are prepared and are investigated in single cylinder, four stroke CI engine computerized test rig. The results obtained on engine performance parameters i.e brake power (bp), brake specific fuel consumption (bsfe) and smoke intensity and presented graphically with respect to the engine coolant temperature at different engine loads ie of 8,12 and $16 \mathrm{~kg}$ etc. The present study inferred that it is preferable to operate the engine at temperature $65^{\circ} \mathrm{C}-75^{\circ} \mathrm{C}$ to obtain best performance indicators.
\end{abstract}

Keywords-CI engine, Jatropha biosiesel, diesel, smoke intensity, operating temperature.

\section{Introduction}

Energy is an essential and vital input for economic activity. It is also the lifeline of modern societies. Building a strong base of energy resources is a pre requisite for sustainable economic and social development of a country. With increasing trend of motorization and industrialization, the world's energy demand is growing at a faster rate.

Today research and development in the field of internal combustion (IC) engines have to face a double challenge; on the one hand fuel consumption has to be reduced, while on the other hand ever more stringent emission standards have to be fulfilled.. The development of engines with its complexity of in-cylinder processes requires modern development tools to exploit the full potential in order to reduce fuel consumption.

Karsoliya R.P., Mandloi R.K

M. A. National Institute of Technology, Bhopal, India
Sharp hike in petroleum prices and increase in environmental pollution jointly have necessitated exploring some renewable indigenous alternatives to conventional petroleum fuels. Also, depletion of fossil fuels, vehicular population, increasing industrialization, extra burden on home economy, growing energy demand, explosion of population, environmental pollution, stringent emission norms (Euro I, II, III, IV), etc emphasize on the need for alternative fuels. The alternative fuels must be technically feasible, environmentally acceptable, readily available and economically competitive.

Bio-diesel, which can be used as an alternative fuel is made from renewable biological sources such as vegetable oils and animal fats. It is bio-degradable, non-toxic and possesses low emission profiles [1]. Also, the use of bio-fuels is environmental friendly. Significant researches have already been put forward in investigating the performance of biodiesel in diesel engine application.

The researchers have reported varying results on power delivered by diesel engine with the use of biodiesel. Some authors have shown power loss while others have shown an increase in rated power and torque. Cetinkaya et al. in 2005 [2] performed experimentation on a $75 \mathrm{~kW}$ four-cylinder common rail engine. They observed that the reduction of torque was only 3 to $5 \%$ with waste oil biodiesel compared to petroleum diesel. Lin et al. in 2006 [3] also carried out experiments on a $2.84 \mathrm{~L}$ naturally aspirated engine and they found $3.5 \%$ less power using pure palm oil biodiesel than that of petroleum diesel at full load condition. Hansen et al. in 1997 [4] also studied the break torque of test engine by varying viscosity, density and heating value of the fuel. They have shown that the break torque loss was $9.1 \%$ when $100 \%$ bio-diesel was used as fuel instead of petroleum diesel at 1900 rpm.

Many researchers have reported an increase in Brake Specific Fuel Consumption (bsfc) when using biodiesel and its blends compared to petroleum diesel fuel. These increases were basically the result of the loss of heating value in the biodiesel fuel blends. [ 5, 6, 7, 8, 9]

In the present scenario the designs of $\mathrm{CI}$ engine being used in automotives by various manufacturers are not properly suitable to Indian climate condition. Looking in to the vast varying atmospheric temperature range in the country it is very difficult to say that which temperature is most suited to operating condition of engines and will give the best performance levels as far as bsfc and bp is concerned. 
After reviewing the literature, applying real experiences, in the experimental investigations and observations it is inferred that the engine systems can be optimized and evolved to provide precision cooling with necessary changes in engine cooling system, to reduce excessive heating and irregular temperature gradient for better performance. A lot of work has been done on the study of performance and emission characteristics of alternate fuels in IC engines. Limited amount of work is done related with temperature effect on CI engines running on bio-diesel. As per the author's point of view, it has been observed that no literature is available on the effect of CI engine operating performance parameters for bio-diesel with changing engine operating temperature related to ambient atmospheric temperatures. The authors are in strong opinion to evaluate the research on engine operating temperature with biodiesel and its blends as this would have definite impact on engine performance.

\section{Engine Test Set Up and Methodology}

A computerized C I engine test rig used for present experimental investigation. This experimental test rig consists of a single cylinder, four strokes, constant speed; direct injection diesel engine is used for the experiments having a rated power output of $5.2 \mathrm{~kW}$ at a constant speed of $1500 \mathrm{rpm}$. The test rig also have eddy current dynamometer as loading system, water cooling system, lubrication system and various sensors and instrumentation integrated with computerized data acquisition system for online measurement of load, air \& fuel flow rate, instantaneous cylinder pressure, position of crank angle, exhaust emissions and smoke opacity etc. Figure 1 shows the photographic image of the experimental setup used in the laboratory to conduct the present study and Figure 2 shows the schematic representation of the experimental test setup.

Commercially available lab-view based engine performance analysis software package "Enginesoft" is used for on line performance data storage. The smoke intensity is measured in terms of Hartridge Smoke Unit (HSU in \%) or in terms of $\mathrm{K}$ (the light absorption coefficient $\left(\mathrm{m}^{-1}\right)$.

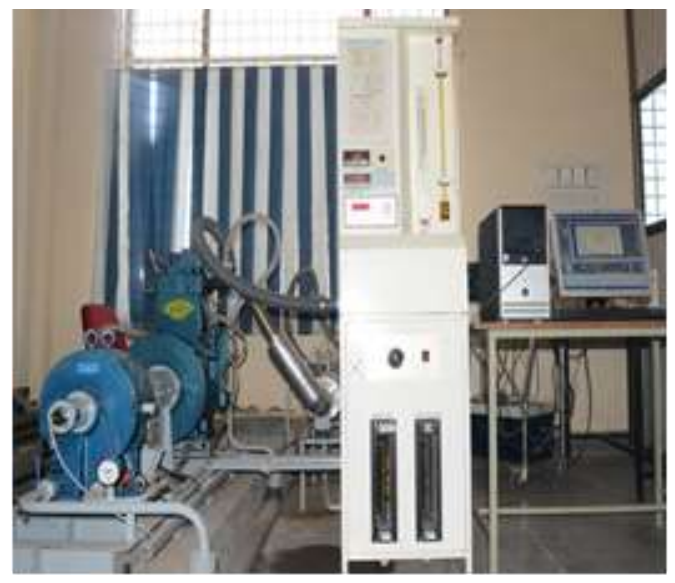

Figure 1. Experimental Set up

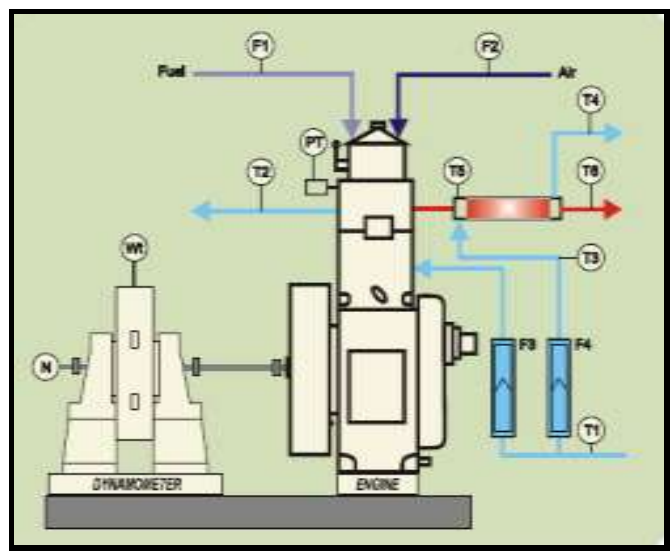

Figure 2. Schematic representation of set up

\section{A. Cylinder Heat Transfer Measurements}

There are a wide range of temperature and heat fluxes in an internal combustion engine. The values of local transient heat fluxes can vary by an order of magnitude depending on the spatial location in the combustion chamber and the crank angle. The source of the heat flux is not only the hot combustion gases, but also the engine friction that occurs between the piston rings and the cylinder wall. When an engine is running at steady state, the heat transfer through out most of the engine structure is steady.

The maximum heat flux through the engine components occurs at fully open throttle and at maximum speed. Peak heat fluxes are in order of 1 to $10 \mathrm{MW} / \mathrm{m} .2$ the heat flux increase with in increases with increasing engine load and speed. The heat flux is largest in the centre of the cylinder head, the exhaust valve seat and the centre of the piston. About $50 \%$ of the heat flow to the engine coolant is through the engine head and valve seats, $30 \%$ through the cylinder sleeve or walls and remaining $20 \%$ through the exhaust port area

\section{B. Effect of Engine Temperature}

Temperature control is very important for combustion engines as temperature is a critical; factor both for chemical reactions and mechanical stresses. Traditionally, temperature control is performed by feedback of a global quantity, the coolant temperature, which however is a poor indicator of specific temperatures. The use of pumps opens flew possibilities for thermal control, in particular in terms of efficiency, but also of pollution, especially in the cold start phase. It shows that predictive control and the use of coolant pumps allow to regulating specific temperatures. [11]. 
Proc. of the Intl. Conf. on Advances in Civil, Structural and Mechanical Engineering - ACSM 2015.

Copyright (C) Institute of Research Engineers and Doctors, USA .All rights reserved.

ISBN: 978-1-63248-039-2 doi: 10.15224/ 978-1-63248-039-2-97

\section{Heat Release and Component Temperature in CI Engines}

The heat flux to the combustion chamber walls varies with engine design and operating condition. Also the heat flux to the various parts of the combustion chamber is not the same. As a result of this nonuniform heat flux and the different thermal impedances between locations on the combustion chamber surface and the cooling fluid, the temperature distribution within engine components is nonuniform. [11].

\section{Effect of Engine Variables}

The following variables affect the magnitude of the heat flux to the different surfaces of the engine combustion chamber and the temperature distribution in the components that comprise the chamber, engine speed, engine load, overall equivalence ratio, compression ratio, injection timing, swirl motion, wall material, mixture inlet temperature, coolant temperature and composition. These variables with speed and load have the greatest effect. [11].

\section{E. Engine Cooling Systems}

There are two types of engine cooling systems used for heat transfer from the engine block and head; liquid cooling and air cooling. With a liquid coolant, the heat is removed through the use of internal cooling channels with in the engine block. Liquid systems are much quieter than air systems, since the cooling channel absorbs the sounds from the combustion process. However, in this experimentation the engine temperature was artificially maintained by controlling the flow rate of coolant to the required fixed temperature.

\section{Results and Discussion}

The performance parameters considered in the present study are bp, brake specific fuel consumption (bsfc) and smoke intensity responding to coolant temperatures considered as engine operating temperature. Thermal Performance Evaluation is carried out in following three different experimental stages;

1. Diesel as fuel at different coolant temperatures and loads.

2. Jatropha bio-diesel as fuel at different coolant temperatures and loads.

3. Blends of Jatropha biodiesel and diesel as fuel at different coolant temperatures and loads.

The blend proportions used to conduct the experiments are B10, B20 and B40.

The blends are prepared by direct mixing of both the fuels in required proportions. Mixing is done with the help of a magnetic mixer. Blends used are as follows;

- $\quad$ B10: $10 \%$ biodiesel and 90\% diesel

- $\quad$ B20: $20 \%$ biodiesel and $80 \%$ diesel
- $\quad$ B40: $40 \%$ biodiesel and 60\% diesel

Figure 3 shows graph between brake power (bp) and coolant water temperature $\left(\mathrm{T}_{2}\right)$ at part load. It is seen from the

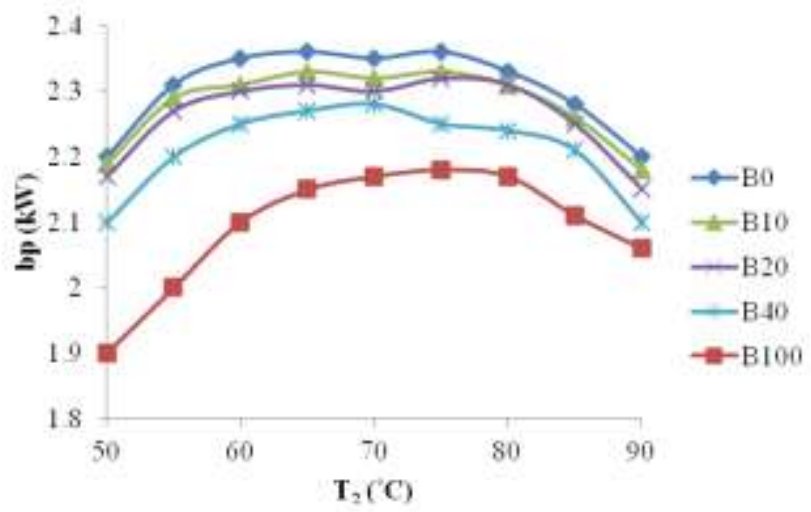

Figure 3. Brake power (bp) of BO, B10, B20, B40 and B100 with different coolant temperatures $\left(T_{2}\right)$ at part load on engine

graph that $\mathrm{bp}$ tends to increase with temperature from $50^{\circ} \mathrm{C}$. This is because the higher wall temperature delays flame quenching on the wall as the quench layer thickness gets reduced and hence the bp increases. The maximum bp occurs at around $65^{\circ} \mathrm{C}-75^{\circ} \mathrm{C}$ for all test fuels considered. With diesel the maximum bp is $2.36 \mathrm{~kW}$ at $65^{\circ} \mathrm{C}$ and at $75{ }^{\circ} \mathrm{C}$ while with biodiesel the maximum bp is $2.18 \mathrm{~kW}$ at $75{ }^{\circ} \mathrm{C}$. Beyond $75{ }^{\circ} \mathrm{C}$ the bp reduces. This is attributed to the fact that volumetric efficiency $(\eta v)$ reduces with increase in operating temperature due to the decrease in air density at higher temperature [11]. It is also seen from the figure that the increase of biodiesel percentage in the blends (B40 and B100) resulted in a decrease of bp over the entire temperature range. This is due to the fact that the higher viscosity and lower heating value of Jatropha oil methyl ester reduces bp. The higher viscosity results in power losses, because the higher viscosity decreases combustion efficiency due to poor fuel injection atomization. It was also found that the B20, B10 and B0 have almost similar bp values. This could be attributed to additional lubricity and presence of oxygen provided by the biodiesel in

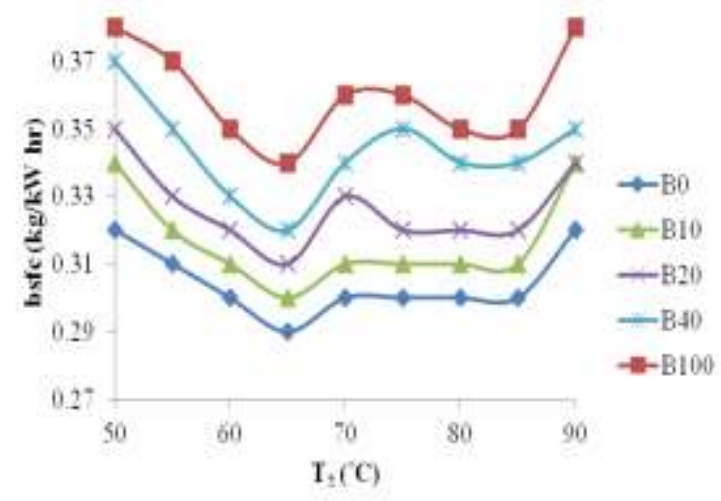

Figure 4. Brake specific fuel consumption (bsfc) of BO, B10, B20, B40 and $B 100$ with different coolant temperatures $\left(T_{2}\right)$ at part load 
blends $\mathrm{B} 20$ and B10 resulting improved combustion and mitigates the effect of higher viscosity and lower heating value of biodiesel.

Figure 4 shows graph between brake specific fuel consumption (bsfc) and coolant water outlet temperature (T2) at part load. It is seen from the graph that bsfc tends to reduce with temperature from $50^{\circ} \mathrm{C}$ because higher temperature ensures complete combustion of fuel. The bsfc is lowest at 65 ${ }^{\circ} \mathrm{C}$ for all test fuels considered. The bsfe increases sharply beyond $85{ }^{\circ} \mathrm{C}$ and becomes maximum at $90{ }^{\circ} \mathrm{C}$. It was also found that pure biodiesel (B100) has higher bsfc than diesel. This may be due to reason that fuel burning rate required is more with jatropha biodiesel because of its lower calorific value.

Figure 5 shows the graph of bp versus coolant temperature (T2) at full load on test engine. It is observed that bp increase with the increase in load as expected. As the load increases from part load to full load the approximate percentage increase in bp for all test fuels is approximately $22-25 \%$. With diesel the maximum bp is $4.54 \mathrm{~kW}$ at $65{ }^{\circ} \mathrm{C}$ while with biodiesel the maximum bp is $4.3 \mathrm{~kW}$ at $65{ }^{\circ} \mathrm{C}$. The minimum bp occurs at temperature $90^{\circ} \mathrm{C}$ for all fuels tested. It is also seen from the figure that the increase of biodiesel percentage in the blends resulted in a decrease of power over the entire temperature

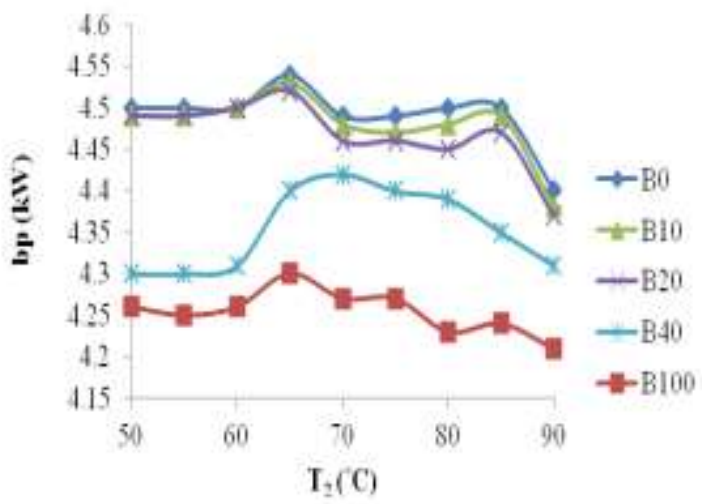

Figure 5. Brake power (bp) of BO, B10, B20, B40 and B100 with different coolant temperatures $\left(T_{2}\right)$ at full load

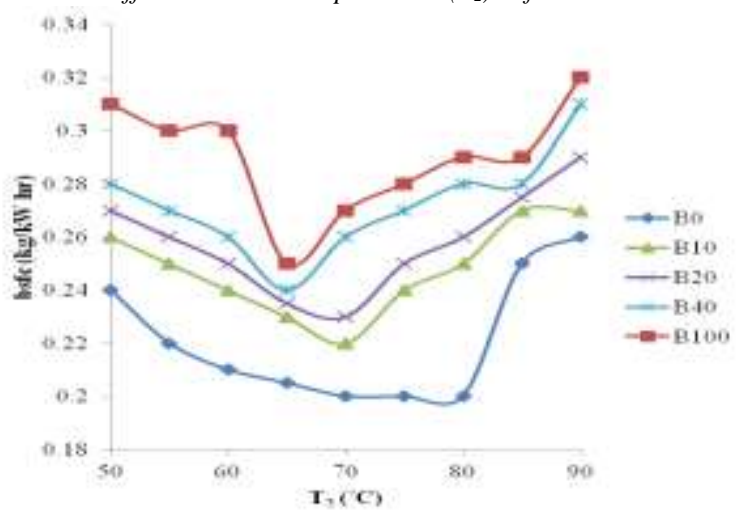

Figure 6. Brake specific fuel consumption of BO, B10, B20, B40 and $B 100$ with different coolant temperatures at full load range.

Figure 6 shows the graph of bsfc versus coolant exit temperature at full load on test engine. It is observed that bsfc decrease with the increase in load. As the load increases from part load to full load the approximate percentage decrease in bsfc for all test fuels is approximately $10-11 \%$. With diesel the lowest bsfc is $0.2 \mathrm{~kg} / \mathrm{kW} \mathrm{hr}$ at $80{ }^{\circ} \mathrm{C}$ and with biodiesel the lowest bsfc is $0.25 \mathrm{~kg} / \mathrm{kW} \mathrm{hr}$ at $65{ }^{\circ} \mathrm{C}$.

Figure 7 illustrates the variation of smoke intensity with engine coolant temperature for all the fuels tested. Smoke intensity is also known as soot or particulate emissions in the form of solid carbon, unburnt hydrocarbons in the exhaust gases. These emissions are a major problem with diesel engine's heterogeneous combustion. Even partial oxidation products are considered under this category. Smoke intensity is measured in Hartridge Smoke Unit (HSU). Higher HSU indicates that either more fuel is burnt or the fuel burning process is hindered by some unfavourable conditions. It is observed from the figure that smoke reduces with increase in coolant temperature for all the fuels. This may be due to a reason that higher temperature cause complete combustion of fuel. As seen from the graph smoke intensity is low for

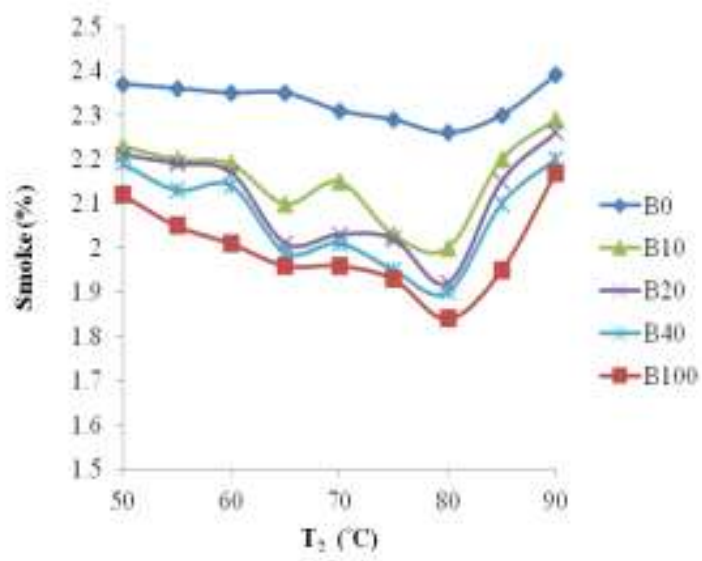

Figure 7. Smoke intensity of $B O, B 10, B 20, B 40$ and $B 100$ with different coolant temperatures $\left(T_{2}\right)$ at part load

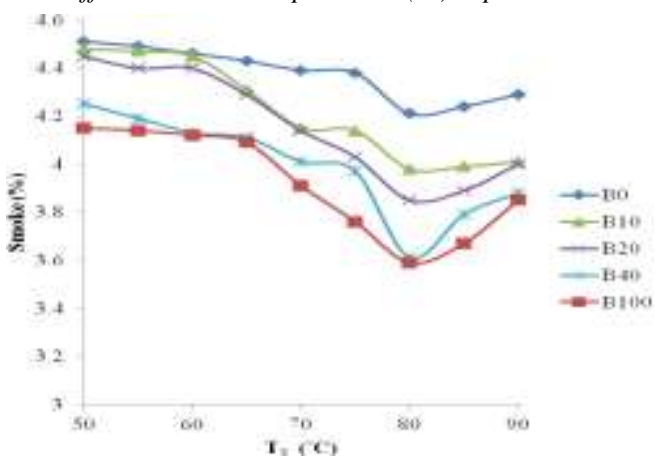

Figure 8. Smoke intensity of BO, B10, B20, B40 and B100 with different coolant temperatures $\left(T_{2}\right)$ at full load 
biodiesel \& its blends which indicate good combustion process with biodiesel. The smoke increases sharply beyond $80{ }^{\circ} \mathrm{C}$ and becomes maximum at $90{ }^{\circ} \mathrm{C}$ which indicates incomplete combustion at higher temperatures.

Figure 8 presents the comparison of variation of smoke intensity with engine coolant temperature for Jatropha biodiesel and its blends with diesel at load of $16 \mathrm{~kg}$. The observed increase in smoke intensity with increase in load may be due to richer mixture being burnt in the cylinder at higher loads. The increase of smoke intensity is approximately $25-27 \%$ for all blends when load is increased from part to full load.

\section{Conclusions}

The experimental study is conducted on a single cylinder, four stroke, constant speed, water-cooled, direct injection diesel engine using Jatropha biodiesel and its blends with diesel. The thermal performance and smoke characteristics were evaluated by running the engine at different combinations of preset engine loads, ranging part to full load, with various coolant temperature at exit from $50^{\circ} \mathrm{C}$ to $90^{\circ} \mathrm{C}$ in steps of $10^{\circ} \mathrm{C}$.

From the experimental investigation on $\mathrm{CI}$ engine following conclusions can be drawn;

1. A single cylinder, four stroke, constant speed, watercooled, direct injection CI engine originally designed to operate on diesel as fuel can also be operated on pure jatropha biodiesel without any system hardware modifications.

2. Based on the observation of graphs of bp versus coolant temperature, it can be concluded that with the increase in coolant temperature, the bp of diesel engine operated using diesel, jatropha biodiesel and its blends tends to increase with temperature from $50^{\circ} \mathrm{C}$. This is because the higher wall temperature delays flame quenching on the wall as the quench layer thickness gets reduced. With diesel the maximum bp is $2.36 \mathrm{~kW}$ at $65^{\circ} \mathrm{C}$ and at $75{ }^{\circ} \mathrm{C}$ while with biodiesel the maximum bp is $2.18 \mathrm{~kW}$ at $75{ }^{\circ} \mathrm{C}$. Beyond $75{ }^{\circ} \mathrm{C}$ the bp reduces due to reduction in volumetric efficiency $(\eta v)$.

3. The increase of biodiesel percentage in the blends resulted in a decrease of bp over the entire temperature range attributed to the fact that the higher viscosity and lower heating value of Jatropha oil methyl ester reduces bp.

4. Based on the observation of graphs of bsfc versus coolant temperature, it can be concluded that bsfc tends to reduce with temperature from $50^{\circ} \mathrm{C}$ and again increases after reaching optimum value and becomes maximum at $90{ }^{\circ} \mathrm{C}$.

5. Because of its lower calorific value pure biodiesel (B100) has higher bsfc than diesel.

6. The smoke increases sharply beyond $80{ }^{\circ} \mathrm{C}$ and becomes maximum at $90{ }^{\circ} \mathrm{C}$ which indicates incomplete combustion at higher temperatures.

7. It is also observed that the smoke intensity is low for jatropha biodiesel \& its blends which indicate good combustion process with biodiesel.
8. The observed increase in smoke intensity with increase in load may be due to richer mixture being burnt in the cylinder at higher loads.

Based upon the performance and emission characteristics of CI engine under investigation it is inferred that engine should operate at coolant temperature of $65^{\circ} \mathrm{C}-75^{\circ} \mathrm{C}$. This experimental result shows that there is a requirement to think about modifications in existing engine cooling system design as per India's climatic condition.

\section{References}

[1] CGIAR, "Biofuels Research in the CGIAR: A Perspective from the Science Council," A CGIAR Science Council Policy Statement on Biofuels Production, Rome, SC Secretariat, April 2008.

[2] M. Cetinkaya, Y Ulusay, Y Tekn and F. Karaosmanoglu, "Engine and winter road test performances of used cooking oil originated biodiesel," Energy Conversion management, vol. 46, pp. 1279-1291, 2005.

[3] Y.C. Lin, W.J. Lee, T.S. Wu and C.T. Wang, "Comparison of PAH and regulated harmful matter emissions from biodiesel blends and paraffinic fuel blends on engine accumulated mileage test," Fuel, vol. 85, pp. 2516-2523, 2006.

[4] K.F. Hansen and M.G. Jensen, "Chemical and biological characteristics of exhaust emissions from a DI diesel engine fuelled with rapeseed oil methyl ester (RME)," International Spring Fuels \& Lubricants Meeting \& Exposition, Paper No. 971689, PA: SAE., 1997.

[5] L. Turrio-Baldassarri, C.L. Battistelli, L. Conti, R. Crebelli, B. De Berardis, et al., "Emission comparison of urban bus engine fuelled with diesel oil and biodiesel blend," Science Total Environment, vol. 327, pp. 147-162. 2004.

[6] R.J. Last, M. Kruger and M. Durnholz, "Emissions and performance characteristics of a 4-stroke, direct injected diesel engine fueled with blends of biodiesel and low sulphur diesel fuel," SAE Paper No. 950054, Warrendale, PA: SAE., 1995.

[7] M. Canakci and J. Van Gerpen, "Biodiesel production from oils and fats with high free fatty acids," American Society of Agricultural Engineers, vol. 44(6), pp. 1429-1436, 2001.

[8] M. Alam, J.Song, R. Acharya, A. Boehman and K.Miller, "Combustion and emissions performance of low sulfur, ultra low sulfur and biodiesel blends in a DI diesel engine," SAE 2004-01-3024.

[9] A. Senatore, M. Cardone, V. Rocco and M.V. Prati, "A comparative analysis of combustion process in D.I. Diesel engine fueled with biodiesel and diesel fuel," SAE 2000-01-0691.

[10] M. Lapuerta, O. Armas and J. Rodriguez-Fernandez, "Effect of biodiesel fuels on diesel engine emissions," Progress in Energy and Combustion Science, vol. 34 (2), pp. 198-223, 2008.

[11] J.B. Heywood, Internal Combustion Engine Fundamentals, McGrawHill, 1988.

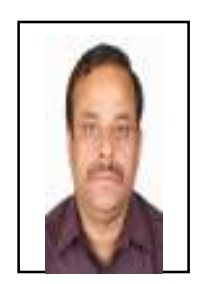

Karsoliya R.P. is a research scholar at M. A. National Institute of Technology, M.A.N.I.T. Bhopal, India (An Institute of National Importance, under Ministry of H.R.D., Govt. of India). 
Proc. of the Intl. Conf. on Advances in Civil, Structural and Mechanical Engineering - ACSM 2015.

Copyright $($ Institute of Research Engineers and Doctors, USA .All rights reserved.

ISBN: 978-1-63248-039-2 doi: 10.15224/ 978-1-63248-039-2-97

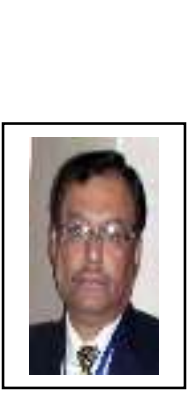

Prof. Mandloi R.K. B. Tech., M. Tech. and Ph.D. Mechanical Engineering

(Automobile Engineering) from (MACT)

now M.A.N.I.T. He joined this institute in 1985 as JRF \& served on different positions in Mechanical Engineering Department. In 2006 became Associate Professor \& Head, Central Workshop, Mechanical Engineering Department, M. A. National Institute of Technology, Bhopal. India 